Published in final edited form as:

Curr Opin Neurol. 2014 August ; 27(4): 450-460. doi:10.1097/WCO.0000000000000118.

\title{
Treatment of advanced Parkinson's disease
}

\author{
Juan C. Giugni, M.D and Michael S. Okun, M.D. \\ Departments of Neurology and Neurosurgery, University of Florida Center for Movement \\ Disorders and Neurorestoration, Gainesville, FL
}

\section{Abstract}

Purpose of the review-Later stage Parkinson's disease (PD), sometimes referred to as advanced disease, has been characterized by motor complication, as well as by the potential emergence non-levodopa responsive motor and non-motor symptoms. The management of advanced stage PD can be complex. This review summarizes the currently available treatment strategies for addressing advanced PD.

Recent findings-We will discuss the latest pharmacological strategies (e.g. inhibitors of dopamine-metabolizing enzymes, dopamine agonists and extended release dopamine formulations) for addressing motor dysfunction. We will summarize the risks and benefits of current invasive treatments. Finally, we will address the current evidence supporting the treatment of non-motor symptoms in the advanced PD patient. We will conclude by detailing the potential non-pharmacological and multidisciplinary approaches for advanced stage PD.

\begin{abstract}
Summary-The optimization of levodopa is in most cases the most powerful therapeutic option available, however medication optimization requires an advanced understanding of PD. Failure of conventional pharmacotherapy, should precipitate a discussion of the potential risks and benefits of more invasive treatments. Currently, there are no comparative studies of invasive treatment. Among the invasive treatments, deep brain stimulation has the largest amount of existing evidence, but also has the highest individual per patient risk. Non-motor symptoms will affect quality of life more than the motor PD symptoms, and these non-motor symptoms should be aggressively treated. Many advanced PD patients will likely benefit from multi- and interdisciplinary PD teams with multiple professionals collaborating to develop a collective and tailored strategy for an individual patient.
\end{abstract}

Corresponding Author: Michael S. Okun, M.D., 3450 Hull Road, Gainesville, FL 32607, 352-294-5400, FAX 352-273-5575, okun@neurology.ufl.edu.

Disclosure of funding received for this work: none funding was received for this work

Conflicts of interest

Dr. Giugni: none declared

Dr. Okun: serves as a consultant for the National Parkinson Foundation, and has received research grants from NIH, NPF, the Michael J. Fox Foundation, the Parkinson Alliance, Smallwood Foundation, the Bachmann-Strauss Foundation, the Tourette Syndrome Association, and the UF Foundation. Dr. Okun has previously received honoraria, but in the past $>48$ months has received no support from industry. Dr. Okun has received royalties for publications with Demos, Manson, Amazon, Smashwords, and Cambridge (movement disorders books). Dr. Okun is an associate editor for New England Journal of Medicine Journal Watch Neurology. Dr. Okun has participated in CME activities on movement disorders (in the last 36) months sponsored by PeerView, Prime, and by Vanderbilt University. The institution and not Dr. Okun receives grants from Medtronic and ANS/St. Jude, and the PI has no financial interest in these grants. Dr. Okun has participated as a site PI and/or co-I for several NIH, foundation, and industry sponsored trials over the years but has not received honoraria. 


\section{Keywords}

Parkinson's; deep brain stimulation; medications; behavioral; selection criteria

\section{Introduction}

Despite the availability of medical and surgical treatments that improve PD motor symptoms, the disease will in the majority of sufferers lead to progressive disability (1). Progression in later stages is characterized by motor complications inclusive of fluctuations and dyskinesia (2). As PD progresses there is an emergence of a symptom constellation that may be non-responsive to levodopa. This resistant symptom complex includes postural instability and falls, speech and swallowing difficulties, and non-motor symptoms (NMS) (3).

Hoehn and Yahr suggested that the mean time of PD progression to disability was seven years in the pre-levodopa era (4). However in the post-levodopa era, the mean time from disease onset to wheelchair-dependence was fourteen years (5). PD progression has been universally associated with increased disability and a diminished quality of life (QoL) (6-8).

Advanced PD is commonly defined by clinicians as stage 4 and 5 on the Hoehn and Yahr scale (4). Other authors have suggested as an alternative definition that the onset of motor complications is a more reasonable description of advanced disease $(6,9,10)$. Additionally, the older definition does not differentiate PD patients who develop levodopa resistant symptoms, and those who become highly dependent on caregivers (11). In this paper we will define advanced PD as the onset of motor complications, despite aggressive pharmacological and behavioral management. We will not exclude patients with NMS and/or levodopa resistant symptoms. We will present an evidence-based review of current treatment options for the management of motor and non-motor complications of advanced PD. (Figure 1)

\section{Treatment of motor complications}

There are several potential mechanisms involved in the development of motor complications. These mechanisms collectively lead to a narrow therapeutic window where low plasma and striatal levels of dopaminergic drugs will lead to OFF periods, and high levels will lead to an increase in peak-dose dyskinesia. It has been estimated that motor complications accrue in 10\% of PD patients per year, and have an estimated 50\% occurrence by five years of disease (12). Other motor signs and symptoms may emerge including gait and postural abnormalities and these increase the risk of falling, dysphagia, dysarthria, and cognitive problems.

\section{Non-invasive treatment for advanced PD}

Non-invasive treatment of advanced PD should focus on the optimization of dopaminergic therapy inclusive of factors such as absorption, timing, dosage(s), and pharmacokinetic and delivery changes. Absorption of levodopa can be delayed by amino acids present in large 
protein containing meals (13) and can be improved by administration one half to one hour before meals. Fractionating the levodopa dosage and changing the time intervals between dosages can be useful (14). These options may impact compliance and ultimately effectiveness $(15,16)$ though failure to do so may also impact therapeutic benefit. Another therapeutic option is to utilize a controlled release formulation. Several clinical trials have failed to reveal a significant reduction in OFF time or an increase in ON time compared to immediate release formulations $(17,18)$. However a recent phase 3 trial comparing IPX066, an oral extended release formulation of carbidopa levodopa, versus immediate release carbidopa levodopa, has shown promising results with a reduction of over one hour of OFF time compared to standard release formulations $(\mathrm{p}<0.0001)\left(19^{* *}\right)$. Since this drug has yet to be released onto the market, it remains unknown whether it can be effective in cases of severe dyskinesia, and whether it can aid in reducing the total number of pills taken in a day.

According to the Movement Disorder Society (MDS) recommendations, rasagiline $1 \mathrm{mg}$ daily as an adjunct to levodopa can be clinically useful for motor fluctuations (20). This recommendation drew its genesis from two clinical trials: PRESTO (21) and LARGO (22). These studies revealed that adding rasagiline 0.5 and $1 \mathrm{mg}$ to levodopa-carbidopa/levodopabenserazide (LC/LB) reduced OFF time and increased ON time in PD patients with motor fluctuations. In the post-hoc analyses of the PRESTO and LARGO studies (23), rasagiline seemed to improve the cardinal PD motor symptoms and to significantly reduce daily OFF time when used as a first line adjunctive therapy for PD patients with mild motor fluctuations. Rasagiline has a reasonable side effect profile (24). Early studies of the generic drug selegiline by the Parkinson Study group, have revealed similar very mild symptomatic improvements in PD motor symptoms and wearing off (25).

Adjunctive entacapone added to LC/LB treatment in patients with moderate and severe PD has been shown to reduce the dose and the frequency of the administration of levodopa, and this strategy has led in many patients to an increase in ON time, and a reduction of OFF time (26). Entacapone was observed to be effective as compared to LC in PD patients with mild motor fluctuations (27). There has however, been a consistent increase in dyskinesia(s) reported in patients taking catechol-O-methyltransferase inhibitors (28). In a prospective double-blind trial, the STRIDE-PD study, the authors compared the risk of developing dyskinesia in PD patients to initiated LC and levodopa/carbidopa/entacapone (LCE) treatment (29). 373 patients in the LCE group and 372 in the LC group were randomized. After 134 weeks, patients receiving LCE had a shorter time to onset dyskinesia with no significant difference in time to wearing off or to motor score. By contrast, the results showed in the FIRST-STEP study where the authors did not observe a difference in motor fluctuations and dyskinesia after randomizing 423 patients in a double-blind study comparing LCE and LC in early PD patients (30). The results of the STRIDE-PD study were sobering (i.e. dyskinesia induction), but also very helpful in instilling a sense of caution when using COMT inhibitors (29). Additionally in the STRIDE-PD study there was an increase in acute myocardial infarction (29), though in more recent studies it was not associated with entacapone (entacapone-treated PD patients) (31).

Long-acting dopamine agonists (DAs) that can be administered once a day have become more popular with patients (32), however in practice sometimes even these formulations 
need to be administered more than once a day (33). The idea of an extended release agonist fits well with the continuous dopaminergic stimulation hypothesis. This hypothesis would support the notion that an extended release formulation would result in less plasma fluctuations, and thus less motor complications (34). This theory has been challenged by many experts (35), and has yet to be completely proven.

Extended versus immediate release pramipexole versus a placebo were compared in PD motor fluctuaters (518 patients were enrolled). Both DA formulations significantly improved UPDRS scores and OFF time when compared to placebo ( $\mathrm{p}<0.0001$ and $\mathrm{p}<0.0001$ ), however there was no significant difference in efficacy, tolerability and safety between groups (36).

The PREPARED study compared ropinirole prolonged release (PR) versus immediate release (IR). It enrolled 343 advanced PD patients, 174 in the PR group and 169 in the IR group. There were 251 patients who completed the study. The primary endpoint was the proportion of patient maintaining $\geq 20 \%$ reduction in OFF time from baseline to week 24 . There was a $66 \%$ improvement in the PR group, and a $51 \%$ improvement in IR group, and this improvement was maintained. There was a $20 \%$ reduction in OFF time from baseline $(\mathrm{p}<0.009)$. However, the mean dosage at the end of the study was $18.6 \mathrm{mg} / \mathrm{d}$ and $10.4 \mathrm{mg} / \mathrm{d}$ respectively (37).

The PREFER trial and the CLEOPATRA-PD study collectively, revealed that rotigotine was superior to placebo in decreasing OFF time $(38,39)$, and was non-inferior to pramipexole (39). In the CLEOPATRA-PD study 506 patients were randomized to receive rotigotine $(n=204)$, Pramipexole $(n=201)$ and placebo $(n=101)$, after 6 months the absolute change in off time from baseline compared to placebo were $-1.58 \mathrm{hs}(\mathrm{p}<0.001)$ and $-1.94(\mathrm{p}<0.001)$ for rotigotine and pramipexole respectively (39). When rotigotine was added to levodopa in another study it revealed significant improvements in nocturnal sleep disturbances, and in early morning motor symptoms (40). In the open-label extensions of the PREFER (SP715) and CLEOPATRA-PD (SP516) trials, 395 patients in SP516 and 256 in SP715 were randomized and it was shown that adjunctive rotigotine treatment in advanced PD patients was efficacious and had a reasonable safety profile at 6 years of follow-up ( $\left.41^{*}\right)$. Rotigitine has a similar side effect profile to other agonists, however it can also result in application related skin reactions (42).

Clinicians should be aware of the dangers of using DAs in the setting of dementia, hallucinations, autonomic dysfunction and sleep disorders. Impulse control disorder (ICD) is another possible side effect of all DAs (43). A recent study evaluated ICD in 223 PD patients taking DAs. The results revealed that $42 \%$ of patients treated with an oral DA developed ICD versus $19 \%$ treated with transdermal rotigotine $(p<0.01)(44)$. These results are interesting as they point to a decrease in unwanted side effects when PD patients receive DAs. Since this research hasn't been replicated, it's unclear if clinicians should choose rotigotine over others in order to avoid these side effects when treating PD patients.

Istradefylline, a selective adenosine $\mathrm{A}_{2 \mathrm{~A}}$ receptor antagonist, was shown to result in a significant reduction in OFF time when employed as an adjunctive therapy in an advanced 
PD cohort (45-47). In a randomized placebo-controlled trial including 373 advanced PD patients, istradefylline 20 and $40 \mathrm{mg}$ /day significantly reduced OFF time ( 0.99 hours and 0.96 hours with $\mathrm{p}<0.003$ and $\mathrm{p}<0.003$ respectively). Induction of dyskinesia was the most common side effect (48*). Istradefylline failed to achieve FDA approval, but it is currently approved and used in Japan. Istradefylline and several other adenosine $\mathrm{A}_{2 \mathrm{~A}}$ receptor antagonists are currently under trial in the US.

\section{Medical management of dyskinesias}

Dyskinesia has a reported incidence in levodopa treated patients of $59 \%$ at 10 years, though only $12 \%$ reported dyskinesia as troublesome and difficult to manage (49). The most common approach to address dyskinesia is to lower the dose of levodopa, and to shorten the time intervals between dosages.

Currently amantadine, an N-methyl-d-aspartate (NMDA) antagonist can be administered at a dose of $100-400 \mathrm{mg} / \mathrm{day}$. Amantadine is the only drug that has been shown to be clearly and directly useful to suppress levodopa-induced dyskinesia (LID) $(20,50)$.

However other drugs and new treatment targets are under investigation for the treatment of dyskinesia (51). A 13-week, double-blind placebo controlled study evaluated the efficacy and safety of AFQ056, a selective metabotropic glutamate receptor 5 antagonist (mGluR). This study of 98 patients revealed that the antidyskinetic efficacy showed promise when examining the response fluctuation item of the UPDRS IV (item 32). This finding was demonstrated with the 50 and $200 \mathrm{mg}$ dosages ( $\mathrm{p}<0.003$ and $\mathrm{p}<0.005$ respectively) $(52 *)$. Currently, clinicians should be aware that the addition of amantadine to frail elderly advanced patients may possibly result in confusion, hallucinations, and worsening of symptoms.

\section{Invasive treatment options to treat motor complications}

There are circumstances when therapeutic management using oral medication will not adequately address motor complications. In this setting patients may benefit from one of three invasive options: 1- continuous subcutaneous apomorphine infusion, 2- continuous duodenal levodopa carbidopa pump, or 3- deep brain stimulation (DBS). Currently there are no large studies comparing and contrasting the procedures. DBS treatment currently has the highest level of evidence (with the most randomized controlled studies). The decision to employ any of the therapies should be made only after employing a multidisciplinary team that has carefully examined and weigh relative risks and benefits of each therapy (53).

\section{Apomorphine}

Apomorphine is D1/D2 DA. Because apomorphine has a rapid onset of action, it is effective in addressing OFF periods through the implementation of rescue injections (54).

Apomorphine is also available as a continuous infusion treatment, and several trials suggest it is effective in treating motor symptoms (55-57) and some non-motor advanced PD symptoms (58). 


\section{Duodopa}

Levodopa carbidopa intestinal gel (LCIG) can be delivered directly to the proximal jejunum via a percutaneous endoscopic gastrojejunostomy (PEG-J) tube connected to a portable infusion pump (53) (Figure 2). This pump therapy can be used to avoid erratic gastric emptying and to improve intestinal absorption (59). Several studies have observed that LCIG is an effective treatment for improving motor fluctuations and quality of life scores when compared to conventional therapy (60-62). In a recent placebo controlled parallel group study including 71 patients with advanced PD, 66 patients completed the trial. There were 35 patients randomly allocated to treatment with LCIG plus oral placebo, and 31 were randomly allocated to treatment with immediate release oral levodopa carbidopa plus placebo intestinal gel. At the end of 12 weeks of treatment with levodopa carbidopa intestinal gel, the infusion showed a significant reduction in OFF time of $-4.04 \mathrm{~h} / \mathrm{day}$ compared with treatment with immediate release oral levodopa carbidopa plus placebo intestinal gel $(2.14 \mathrm{~h} /$ day $\mathrm{p}<0.0015)$. This improvement was also observed in ON time without troublesome dyskinesia ( $\mathrm{p}<0.0059)$, and in ON time without dyskinesia $(\mathrm{p}<0.0142)$. Similar to the other studies, $95 \%$ of patients in the levodopa carbidopa intestinal gel group had an AE, and $14 \%$ of them an SAE. Interestingly $100 \%$ in the placebo group had AEs, and $21 \%$ had an SAE. Most of the complications of the pump therapy were associated with the percutaneous gastrojejunostomy $\left(63^{* *}\right)$. Though available in 43 countries this therapy is not currently available in the US.

\section{Deep brain stimulation (DBS)}

DBS is functional neurosurgical technique that can be employed to treat motor fluctuations, dyskinesia, and tremor. There have been three recent randomized controlled clinical trials comparing GPi and/or STN versus best medical management for advanced PD. These trials have provided support for the notion that in many fluctuating patients, DBS is superior to medication therapy, and may also enhance quality of life (64-66) (Table 1). In the German Parkinson Study Group trial (64) after 6 months of bilateral STN DBS therapy there was a significant improvement in both motor function and quality of life. Similarly in the CSP 468 Veteran's Administration Study Group (65), a total of 255 patients were enrolled and randomized to STN or GPi DBS. There was also a best medical therapy group. After 6 months, the DBS group revealed a mean of 4.6 hours/day of on time without troublesome dyskinesia as compared with 0 hours in the best medical therapy group $(\mathrm{p}<0.001)$, and motor outcomes were similar for STN and GPi. The PD SURG Collaborative Study Group (66) included 366 patients in the United Kingdom and it reported an improved in quality of life (PDQ-39) of 5.0 points in the DBS group and 0.3 points in the medical treatment group over a 1-year follow up period $(\mathrm{p}<0.001)$.

There are however, important decisions for clinicians considering DBS therapy including the most appropriate target for an individual patient (STN vs. GPi). Several trials have compared both targets and had similar motor results (67-70). Depressive symptoms may have been less frequent in GPi patients $(71 *)$. Appropriate patient selection is the most critical factor for successful DBS, and this selection process can be best accomplished through the use of an interdisciplinary team $(72,73)$. 
It is important to recognize that in advanced PD, symptoms unresponsive to levodopa such as cognitive impairment, gait instability, mood disorders, speech impairment and autonomic dysfunction are unlikely to improve with DBS, and could even worsen $(74,75)$. There is a search for other targets to address levodopa resistant symptoms, and the most information available has been on the use of pedunculopontine nucleus and $\mathrm{SNr}$ stimulation which may improve gait and balance $(76,77)$ in some patients, though their use is still limited to research. Not all experts agree that PPN stimulation is an effective way to treat gait and balance, and some of the issues may be due to lead location relative to the appropriate fibers and connections (78), and due to the technique of applying stimulation (parameters and schedule).

\section{Treatment of balance and gait disorders}

Despite many treatments available for advanced PD, the management of postural instability and gait disorders have yet to be fully elucidated. Trials of apomorphine continuous infusion and LCIG have reported some improvement in gait and postural problems $(56,60)$, but not beyond what can be achieved with medication therapy. Physical, occupational and exercise therapy can all be helpful in the symptomatic treatment of advanced PD (79). Both tai chi and resistance exercises have been shown to reduce the risk of falling (80).

\section{Treatment of non-motor symptoms}

Despite the recognition of NMS and the impact of NMS on quality of life, treatment is still not completely established for many of the symptoms (81). The first step in the treatment of NMS, following a search for a secondary cause. Some clinicians discontinue many medications but it should be appreciated that this approach may potentially worsen motor symptoms, so caution should be exercised, and carefully monitoring sought (82)

\section{Dementia}

Currently, rivastigmine, a cholinesterase inhibitor, is the only FDA approved medication for the treatment of mild to moderate PDD, and rivastigmine is the only agent with efficacy data in PDD $(81,83)$. In a double-blind randomized study of 541 patients with PDD (MMSE 1024), a significant improvement in dementia was seen at 24-weeks (83). This improvement in PDD was maintained in the extension of this trial, which was a long-term treatment study (up to 48 weeks) (84). In a 76-week randomized open label study of rivastigmine $12 \mathrm{md} / \mathrm{d}$ capsules and $9.5 \mathrm{mg} / 24 \mathrm{~h}$ patch, 583 patients were randomized (85). The incidence of AEs due to worsening of PD was $36.1 \%$ in the capsule group with tremor the most frequently reported $(24.5 \% ; 95 \% \mathrm{CI})$. In the patch group AEs due to worsening of PD were $31.9 \%$, however tremor was reported in $9.7 \%$ (95\% CI). In both groups there was a 2.1 point worsening on the UPDRS-III motor scale. The efficacy was comparable to results in previous trials $(83,84)$. Donepezil, galantamine and memantine have been evaluated for the treatment of PDD in different trials (86-88), but their efficacy has not been clearly demonstrated (81). 


\section{Psychosis and hallucinations}

Clozapine is the only antipsychotic drug that has revealed efficacy for the treatment of PD psychosis across clinical trials (81), however the risk of agranulocytosis and the need for frequent blood draws has limited its use. Quetiapine is safer than clozapine, however studies have revealed that it is much weaker when employed for the treatment of PD psychosis (81). Pimavanserin, a select serotonin 5-HT2A inverse agonist, has shown evidence of benefits and tolerability in treating PD psychosis and it does not block dopamine receptors, and thus does not worsen PD $(89,90)$. In a 6-week randomized, double-blind, placebo-controlled trial in 199 patients, the safety and efficacy of pimavenserin was assessed. The patients in the pimavenserin group showed a decrease of 5.79 points in the mean PD-adapted scale for assessment of positive symptoms (SAPS-PD) as compared with 2.73 for the placebo group $(\mathrm{p}=0.001)$. Additionally, patients in the pimavenserin group had greater improvement on the clinical global impression scale and the caregiver burden scale. Pimavenserin was well tolerated with no worsening of motor function $\left(90^{* *}\right)$

\section{Depression, anxiety and apathy}

Currently, tricyclic antidepressants (TCA's) may be the best choice to treat depression in $\mathrm{PD}$, followed by serotonin reuptake inhibitors (SSRI's), and in some cases dopaminergic therapy (91) Cognitive behavioral therapy (CBT) appears to be a promising treatment. (92). Most experts in the field use traditional SSRI's, SNRI's or a TCA and will follow the PD patient closely in 4-6 weeks, and adjust therapy as needed. In exceptionally severe cases, transcranial magnetic stimulation (TMS) or electroconvulsive therapy (ECT) is used. No established treatment for apathy is available. Methylphenidate, levodopa, selegiline and antidepressants have been suggested to be useful $(93,94)$. In a small double-bind, randomized trial, rivastigmine $9.5 \mathrm{mg} /$ day transdermal patch improved the Lille Apathy Rating Scale (LARS) from -11.5 at baseline to -20 after treatment and the improvement exceeded placebo $(\mathrm{p}=0.031)(95)$. There was also improvement in the instrumental activity of daily living scale, and caregiver burden, but not the quality of life. Though there is a lack of literature on the subject many experts use a DA for severe apathy, but do so with an abundance of caution for impulsive behaviors.

\section{Autonomic Failure}

The first step to treat orthostatic hypotension $(\mathrm{OH})$ should be non-pharmacologic methods, such as elastic stockings/abdominal compression bands, fragmentation of meals, increased water and salt intake, avoidance of alcohol consumption, night time head-up-tilt, and physical counter-maneuvers (96). OH is often accompanied by supine hypertension, therefore the treatment should aim at minimizing $\mathrm{OH}$ without exacerbating supine hypertension. Fludrocortisone and midodrine are commonly used to treat $\mathrm{OH}$, but could worsen supine hypertension (97). Interim exploratory analysis of $51 \mathrm{PD}$ patients with $\mathrm{OH}$ enrolled in a phase 3 study of droxidopa (L-threo-3,4-dihydroxyphenylserine) (98), failed to show benefit with droxidopa as compared to placebo. The study was stopped, though recently a new study has been exploring the potential of this drug in OH. The FDA has 
recently approved droxidopa for treatment of neurogenic $\mathrm{OH}$, but it is still unclear how effective this therapy will be in clinical practice.

\section{Sleep disorders}

Clonazepam and melatonin are commonly used to treat REM sleep behavior disorder (RBD), and both are well tolerated $(99,100)$, but there is a worry that clonazepam may contribute to cognitive issues and falling, and that melatonin will be ineffective. Modafinil is an option to treat excessive daytime sleepiness, but evidence has not supported its use (81). Cognitive behavior therapy with bright light therapy or doxepin $10 \mathrm{mg} /$ day substantially improved insomnia in PD in a recent small randomized study (101). For advanced PD most practitioners use sleep hygiene, and/or a light dose of a benzodiazepine particularly for RBD. If these therapies are not effective, most experts proceed rapidly to a sleep study.

\section{Pain}

Pain will occasionally respond to optimization of dopaminergic treatment (102). Dystonic focal pain may respond to botulinum toxin injections (103). Other treatments including NSAIDs, opiates, antidepressants, and rTMS have all been found effective in PD pain (104). Clinicians should be aware that prescribing narcotics could increase fall risk, aggravate constipation, and could worsen PD symptoms.

\section{Non-pharmacological treatment in advanced PD}

Non-pharmacological treatments inclusive of physical therapy, occupational therapy, speech therapy, swallowing therapy, and counseling psychology may all be very helpful in PD. Many patients with advanced PD will benefit from integration of these interdisciplinary therapies when appropriate $(20,105-108)$.

\section{Conclusion}

Despite recent new therapies and a better understanding of PD, the disease will ultimately lead to progressive disability in most sufferers. In advanced PD, optimization of dopaminergics is a powerful therapeutic option. In select cases, advanced PD patients will benefit from invasive treatments. DBS has the highest level of evidence for invasive treatments, however results of LCIG trials should make this option a possibility for some sufferers. The management of levodopa resistant PD symptoms, as well non-motor symptoms, can affect quality of life more than the management of typical motor symptoms. Interdisciplinary therapy inclusive of physical therapy, occupational therapy, speech therapy, swallowing therapy and counseling psychology may be helpful in advanced PD.

\section{Supplementary Material}

Refer to Web version on PubMed Central for supplementary material. 


\section{Acknowledgments}

We would like to acknowledge the support of the NPF PD Center of Excellence and the Bachmann-Strauss Dystonia and Parkinson's Disease Center of Excellence.

\section{References}

1. Shulman LM, Gruber-Baldini AL, Anderson KE, et al. The evolution of disability in Parkinson disease. Movement disorders: official journal of the Movement Disorder Society. 2008; 23(6):7906. [PubMed: 18361474]

2. Hauser RA, McDermott MP, Messing S. Factors associated with the development of motor fluctuations and dyskinesias in Parkinson disease. Archives of neurology. 2006; 63(12):1756-60. [PubMed: 17172616]

3. Hely MA, Morris JG, Reid WG, Trafficante R. Sydney Multicenter Study of Parkinson's disease: non-L-dopa-responsive problems dominate at 15 years. Movement disorders: official journal of the Movement Disorder Society. 2005; 20(2):190-9. [PubMed: 15551331]

4. Hoehn MM, Yahr MD. Parkinsonism: onset, progression and mortality. Neurology. 1967; 17(5): 427-42. [PubMed: 6067254]

5. Hoehn MM. Parkinsonism treated with levodopa: progression and mortality. Journal of neural transmission Supplementum. 1983; 19:253-64. [PubMed: 6583311]

6. Chapuis S, Ouchchane L, Metz O, et al. Impact of the motor complications of Parkinson's disease on the quality of life. Movement disorders: official journal of the Movement Disorder Society. 2005; 20(2):224-30. [PubMed: 15384126]

7. Pechevis M, Clarke CE, Vieregge P, et al. Effects of dyskinesias in Parkinson's disease on quality of life and health-related costs: a prospective European study. European journal of neurology: the official journal of the European Federation of Neurological Societies. 2005; 12(12):956-63. [PubMed: 16324089]

8. Santos-Garcia D, de la Fuente-Fernandez R. Impact of non-motor symptoms on health-related and perceived quality of life in Parkinson's disease. Journal of the neurological sciences. 2013; 332(12):136-40. [PubMed: 23890935]

9. Papapetropoulos S, Mash DC. Motor fluctuations and dyskinesias in advanced/end stage Parkinson's disease: a study from a population of brain donors. Journal of neural transmission. 2007; 114(3):341-5. [PubMed: 17146589]

10. Schrag A, Dodel R, Spottke A, et al. Rate of clinical progression in Parkinson's disease. A prospective study. Movement disorders: official journal of the Movement Disorder Society. 2007; 22(7):938-45. [PubMed: 17415791]

11. Coelho M, Ferreira JJ. Late-stage Parkinson disease. Nature reviews Neurology. 2012; 8(8):43542.

12. Lang AE, Lozano AM. Parkinson's disease. Second of two parts. The New England journal of medicine. 1998; 339(16):1130-43. [PubMed: 9770561]

13. Deleu D, Northway MG, Hanssens Y. Clinical pharmacokinetic and pharmacodynamic properties of drugs used in the treatment of Parkinson's disease. Clinical pharmacokinetics. 2002; 41(4):261309. [PubMed: 11978145]

14. Antonini A, Chaudhuri KR, Martinez-Martin P, Odin P. Oral and infusion levodopa-based strategies for managing motor complications in patients with Parkinson's disease. CNS drugs. 2010; 24(2):119-29. [PubMed: 20088619]

15. Pilleri M, Antonini A. Novel levodopa formulations in the treatment of Parkinson's disease. Expert review of neurotherapeutics. 2014; 14(2):143-9. [PubMed: 24428803]

16. Grosset KA, Reid JL, Grosset DG. Medicine-taking behavior: implications of suboptimal compliance in Parkinson's disease. Movement disorders: official journal of the Movement Disorder Society. 2005; 20(11):1397-404. [PubMed: 16092116]

17. Lieberman A, Gopinathan G, Miller E, et al. Randomized double-blind cross-over study of Sinemet-controlled release (CR4 50/200) versus Sinemet 25/100 in Parkinson's disease. European neurology. 1990; 30(2):75-8. [PubMed: 2340838] 
18. Pahwa R, Factor SA, Lyons KE, et al. Practice Parameter: treatment of Parkinson disease with motor fluctuations and dyskinesia (an evidence-based review): report of the Quality Standards Subcommittee of the American Academy of Neurology. Neurology. 2006; 66(7):983-95. [PubMed: 16606909]

19**. Hauser RA, Hsu A, Kell S, et al. Extended-release carbidopa-levodopa (IPX066) compared with immediate-release carbidopa-levodopa in patients with Parkinson's disease and motor fluctuations: a phase 3 randomised, double-blind trial. Lancet neurology. 2013; 12(4):346-56. In this phase 3 study at 68 centers, the authors compared a new oral extended-release carvidopalevodopa (IPX066) versus inmediate-release formulation. IPX reduced daily off-time an extra $1.17 \mathrm{~h}$. With mean of 3.6 dose per day, versus 5.0 in the inmediate-release. The most comon AEs were insomnia, nausea and falls. IPX may be benefits in reduced off-time and reducing levodopa dosing. [PubMed: 23485610]

20. Fox SH, Katzenschlager R, Lim SY, et al. The Movement Disorder Society Evidence-Based Medicine Review Update: Treatments for the motor symptoms of Parkinson's disease. Movement disorders: official journal of the Movement Disorder Society. 2011; 26 (Suppl 3):S2-41. [PubMed: 22021173]

21. Parkinson Study G. A randomized placebo-controlled trial of rasagiline in levodopa-treated patients with Parkinson disease and motor fluctuations: the PRESTO study. Archives of neurology. 2005; 62(2):241-8. [PubMed: 15710852]

22. Rascol O, Brooks DJ, Melamed E, et al. Rasagiline as an adjunct to levodopa in patients with Parkinson's disease and motor fluctuations (LARGO, Lasting effect in Adjunct therapy with Rasagiline Given Once daily, study): a randomised, double-blind, parallel-group trial. Lancet. 2005; 365(9463):947-54. [PubMed: 15766996]

23. Elmer LW. Rasagiline adjunct therapy in patients with Parkinson's disease: post hoc analyses of the PRESTO and LARGO trials. Parkinsonism \& related disorders. 2013; 19(11):930-6. [PubMed: 23849501]

24. Olanow CW, Rascol O, Hauser R, et al. A double-blind, delayed-start trial of rasagiline in Parkinson's disease. The New England journal of medicine. 2009; 361(13):1268-78. [PubMed: 19776408]

25. Shoulson I, Oakes D, Fahn S, et al. Impact of sustained deprenyl (selegiline) in levodopa-treated Parkinson's disease: a randomized placebo-controlled extension of the deprenyl and tocopherol antioxidative therapy of parkinsonism trial. Annals of neurology. 2002; 51(5):604-12. [PubMed: 12112107]

26. Brooks DJ, Leinonen M, Kuoppamaki M, Nissinen H. Five-year efficacy and safety of levodopa/ DDCI and entacapone in patients with Parkinson's disease. Journal of neural transmission. 2008; 115(6):843-9. [PubMed: 18259682]

27. Tolosa E, Hernandez B, Linazasoro G, et al. Efficacy of levodopa/carbidopa/entacapone versus levodopa/carbidopa in patients with early Parkinson's disease experiencing mild wearing-off: a randomised, double-blind trial. Journal of neural transmission. 2014; 121(4):357-66. [PubMed: 24253234]

28. Stocchi F. The levodopa wearing-off phenomenon in Parkinson's disease: pharmacokinetic considerations. Expert opinion on pharmacotherapy. 2006; 7(10):1399-407. [PubMed: 16805724]

29. Stocchi F, Rascol O, Kieburtz K, et al. Initiating levodopa/carbidopa therapy with and without entacapone in early Parkinson disease: the STRIDE-PD study. Annals of neurology. 2010; 68(1): 18-27. [PubMed: 20582993]

30. Hauser RA, Panisset M, Abbruzzese G, et al. Double-blind trial of levodopa/carbidopa/entacapone versus levodopa/carbidopa in early Parkinson's disease. Movement disorders: official journal of the Movement Disorder Society. 2009; 24(4):541-50. [PubMed: 19058133]

31. Graham DJ, Williams JR, Hsueh YH, et al. Cardiovascular and mortality risks in Parkinson's disease patients treated with entacapone. Movement disorders: official journal of the Movement Disorder Society. 2013; 28(4):490-7. [PubMed: 23443994]

32. Schapira AH, Barone P, Hauser RA, et al. Patient-reported convenience of once-daily versus threetimes-daily dosing during long-term studies of pramipexole in early and advanced Parkinson's disease. European journal of neurology: the official journal of the European Federation of Neurological Societies. 2013; 20(1):50-6. [PubMed: 22537207] 
33. Yun JY, Kim HJ, Lee JY, et al. Comparison of once-daily versus twice-daily combination of ropinirole prolonged release in Parkinson's disease. BMC neurology. 2013; 13:113. [PubMed: 24004540]

34. Olanow CW, Obeso JA, Stocchi F. Continuous dopamine-receptor treatment of Parkinson's disease: scientific rationale and clinical implications. Lancet neurology. 2006; 5(8):677-87. [PubMed: 16857573]

35. Olanow CW, Obeso JA, Stocchi F. Drug insight: Continuous dopaminergic stimulation in the treatment of Parkinson's disease. Nature clinical practice Neurology. 2006; 2(7):382-92.

36. Schapira AH, Barone P, Hauser RA, et al. Extended-release pramipexole in advanced Parkinson disease: a randomized controlled trial. Neurology. 2011; 77(8):767-74. [PubMed: 21832216]

37. Stocchi F, Giorgi L, Hunter B, Schapira AH. PREPARED: Comparison of prolonged and immediate release ropinirole in advanced Parkinson's disease. Movement disorders: official journal of the Movement Disorder Society. 2011; 26(7):1259-65. [PubMed: 21469195]

38. LeWitt PA, Lyons KE, Pahwa R, Group SPS. Advanced Parkinson disease treated with rotigotine transdermal system: PREFER Study. Neurology. 2007; 68(16):1262-7. [PubMed: 17438216]

39. Poewe WH, Rascol O, Quinn N, et al. Efficacy of pramipexole and transdermal rotigotine in advanced Parkinson's disease: a double-blind, double-dummy, randomised controlled trial. Lancet neurology. 2007; 6(6):513-20.

40. Trenkwalder C, Kies B, Rudzinska M, et al. Rotigotine effects on early morning motor function and sleep in Parkinson's disease: a double-blind, randomized, placebo-controlled study (RECOVER). Movement disorders: official journal of the Movement Disorder Society. 2011; 26(1):90-9. [PubMed: 21322021]

$41 *$. LeWitt PA, Boroojerdi B, Surmann E, et al. Rotigotine transdermal system for long-term treatment of patients with advanced Parkinson's disease: results of two open-label extension studies, CLEOPATRA-PD and PREFER. Journal of neural transmission. 2013; 120(7):1069-81. In this study, the authors evaluated safety, tolerability and efficacy of rotigotine for up to 6 years. In this long follow-up, adjunctive rotigotine was efficacious with safty profile. [PubMed: 23208198]

42. Lyons KE, Pahwa R. Outcomes of rotigotine clinical trials: effects on motor and nonmotor symptoms of Parkinson's disease. Neurologic clinics. 2013; 31(3 Suppl):S51-9. [PubMed: 23931954]

43. Perez-Lloret S, Rey MV, Fabre N, et al. Prevalence and pharmacological factors associated with impulse-control disorder symptoms in patients with Parkinson disease. Clinical neuropharmacology. 2012; 35(6):261-5. [PubMed: 23123689]

44. Garcia-Ruiz PJ, Martinez Castrillo JC, Alonso-Canovas A, et al. Impulse control disorder in patients with Parkinson's disease under dopamine agonist therapy: a multicentre study. Journal of neurology, neurosurgery, and psychiatry. 2014 Epub ahead of print.

45. LeWitt PA, Guttman M, Tetrud JW, et al. Adenosine A2A receptor antagonist istradefylline (KW-6002) reduces “off” time in Parkinson's disease: a double-blind, randomized, multicenter clinical trial (6002-US-005). Annals of neurology. 2008; 63(3):295-302. [PubMed: 18306243]

46. Stacy M, Silver D, Mendis T, et al. A 12-week, placebo-controlled study (6002-US-006) of istradefylline in Parkinson disease. Neurology. 2008; 70(23):2233-40. [PubMed: 18519872]

47. Hauser RA, Shulman LM, Trugman JM, et al. Study of istradefylline in patients with Parkinson's disease on levodopa with motor fluctuations. Movement disorders: official journal of the Movement Disorder Society. 2008; 23(15):2177-85. [PubMed: 18831530]

48*. Mizuno Y, Kondo T. Japanese Istradefylline Study G. Adenosine A2A receptor antagonist istradefylline reduces daily OFF time in Parkinson's disease. Movement disorders: official journal of the Movement Disorder Society. 2013; 28(8):1138-41. In this trial, istradenafylline, a selective adenosine $\mathrm{A}_{2 \mathrm{~A}}$ receptor antagonist, reduced dailly off time with good tolerance. This drugs is currently available in Japan. this trial sowed a safty profile of this kind of drugs. [PubMed: 23483627]

49. Politis M, Wu K, Molloy S, et al. Parkinson's disease symptoms: the patient's perspective. Movement disorders: official journal of the Movement Disorder Society. 2010; 25(11):1646-51. [PubMed: 20629164] 
50. Rodnitzky RL, Narayanan NS. Amantadine's role in the treatment of levodopa-induced dyskinesia. Neurology. 2014; 82(4):288-9. [PubMed: 24371305]

51. Bargiotas P, Konitsiotis S. Levodopa-induced dyskinesias in Parkinson's disease: emerging treatments. Neuropsychiatric disease and treatment. 2013; 9:1605-17. [PubMed: 24174877]

52*. Stocchi F, Rascol O, Destee A, et al. AFQ056 in Parkinson patients with levodopa-induced dyskinesia: 13-week, randomized, dose-finding study. Movement disorders: official journal of the Movement Disorder Society. 2013; 28(13):1838-46. In this study a novel and promising selective metabotropic glutamate receptor 5 antagonist demonstred anti-dyskinetic efficacy without worsing motor symptoms. This results are promising and showed the differents targets to treat LID. [PubMed: 23853029]

53. Volkmann J, Albanese A, Antonini A, et al. Selecting deep brain stimulation or infusion therapies in advanced Parkinson's disease: an evidence-based review. Journal of neurology. 2013; 260(11): 2701-14. [PubMed: 23287972]

54. Pfeiffer RF, Gutmann L, Hull KL Jr, et al. Continued efficacy and safety of subcutaneous apomorphine in patients with advanced Parkinson's disease. Parkinsonism \& related disorders. 2007; 13(2):93-100. [PubMed: 17055329]

55. De Gaspari D, Siri C, Landi A, et al. Clinical and neuropsychological follow up at 12 months in patients with complicated Parkinson's disease treated with subcutaneous apomorphine infusion or deep brain stimulation of the subthalamic nucleus. Journal of neurology, neurosurgery, and psychiatry. 2006; 77(4):450-3.

56. Garcia Ruiz PJ, Sesar Ignacio A, Ares Pensado B, et al. Efficacy of long-term continuous subcutaneous apomorphine infusion in advanced Parkinson's disease with motor fluctuations: a multicenter study. Movement disorders: official journal of the Movement Disorder Society. 2008; 23(8):1130-6. [PubMed: 18442107]

57. Morgante L, Basile G, Epifanio A, et al. Continuous apomorphine infusion (CAI) and neuropsychiatric disorders in patients with advanced Parkinson's disease: a follow-up of two years. Archives of gerontology and geriatrics Supplement. 2004; (9):291-6. [PubMed: 15207426]

58. Martinez-Martin P, Reddy P, Antonini A, et al. Chronic subcutaneous infusion therapy with apomorphine in advanced Parkinson's disease compared to conventional therapy: a real life study of non motor effect. Journal of Parkinson's disease. 2011; 1(2):197-203.

59. Antonini A, Odin P. Pros and cons of apomorphine and L-dopa continuous infusion in advanced Parkinson's disease. Parkinsonism \& related disorders. 2009; 15 (Suppl 4):S97-100. [PubMed: 20123567]

60. Nyholm D. Duodopa(R) treatment for advanced Parkinson's disease: a review of efficacy and safety. Parkinsonism \& related disorders. 2012; 18(8):916-29. [PubMed: 22824056]

61. Foltynie T, Magee C, James C, et al. Impact of Duodopa on Quality of Life in Advanced Parkinson's Disease: A UK Case Series. Parkinson's disease. 2013; 2013:362908.

62. Fernandez HH, Vanagunas A, Odin P, et al. Levodopa-carbidopa intestinal gel in advanced Parkinson's disease open-label study: interim results. Parkinsonism \& related disorders. 2013; 19(3):339-45. [PubMed: 23287001]

$63^{* *}$. Olanow CW, Kieburtz K, Odin P, et al. Continuous intrajejunal infusion of levodopa-carbidopa intestinal gel for patients with advanced Parkinson's disease: a randomised, controlled, doubleblind, double-dummy study. Lancet neurology. 2014; 13(2):141-9. This study is the first, doubleblind study who compared LCIG vs intestinal gel placebo. Showing good beneffits and safty profile, however severals complication to the pump therapy were evidents. This results are very promising. More safty studies are needed. [PubMed: 24361112]

64. Deuschl G, Schade-Brittinger C, Krack P, et al. A randomized trial of deep-brain stimulation for Parkinson's disease. The New England journal of medicine. 2006; 355(9):896-908. [PubMed: 16943402]

65. Weaver FM, Follett K, Stern M, et al. Bilateral deep brain stimulation vs best medical therapy for patients with advanced Parkinson disease: a randomized controlled trial. JAMA: the journal of the American Medical Association. 2009; 301(1):63-73. [PubMed: 19126811] 
66. Williams A, Gill S, Varma T, et al. Deep brain stimulation plus best medical therapy versus best medical therapy alone for advanced Parkinson's disease (PD SURG trial): a randomised, openlabel trial. Lancet neurology. 2010; 9(6):581-91. [PubMed: 20434403]

67. Okun MS, Foote KD. Subthalamic nucleus vs globus pallidus interna deep brain stimulation, the rematch: will pallidal deep brain stimulation make a triumphant return? Archives of neurology. 2005; 62(4):533-6. [PubMed: 15824249]

68. Okun MS, Fernandez HH, Wu SS, et al. Cognition and mood in Parkinson's disease in subthalamic nucleus versus globus pallidus interna deep brain stimulation: the COMPARE trial. Annals of neurology. 2009; 65(5):586-95. [PubMed: 19288469]

69. Follett KA, Weaver FM, Stern M, et al. Pallidal versus subthalamic deep-brain stimulation for Parkinson's disease. The New England journal of medicine. 2010; 362(22):2077-91. [PubMed: 20519680]

70. Odekerken VJ, van Laar T, Staal MJ, et al. Subthalamic nucleus versus globus pallidus bilateral deep brain stimulation for advanced Parkinson's disease (NSTAPS study): a randomised controlled trial. Lancet neurology. 2013; 12(1):37-44. [PubMed: 23168021]

71*. Sako W, Miyazaki Y, Izumi Y, Kaji R. Which target is best for patients with Parkinson's disease? A meta-analysis of pallidal and subthalamic stimulation. Journal of neurology, neurosurgery, and psychiatry. 2014 Epub ahead of print In this large meta-analysis four studies including 502 PD patients of pallidal and subthalamic stimulation were compared. And they concluded that the effects of both targets were similar exept for depression as adverse events. Therefore additional randomised trials with direct comparision between targets are needed.

72. Okun MS, Foote KD. Parkinson's disease DBS: what, when, who and why? The time has come to tailor DBS targets. Expert review of neurotherapeutics. 2010; 10(12):1847-57. [PubMed: 21384698]

73. Martinez-Ramirez D, Okun MS. Rationale and clinical pearls for primary care doctors referring patients for deep brain stimulation. Gerontology. 2014; 60(1):38-48. [PubMed: 24193201]

74. Bernal-Pacheco O, Oyama G, Foote KD, et al. Taking a better history for behavioral issues preand post-deep brain stimulation: issues missed by standardized scales. Neuromodulation: journal of the International Neuromodulation Society. 2013; 16(1):35-9. discussion 9-40. [PubMed: 22748071]

75. Rocchi L, Carlson-Kuhta P, Chiari L, et al. Effects of deep brain stimulation in the subthalamic nucleus or globus pallidus internus on step initiation in Parkinson disease: laboratory investigation. Journal of neurosurgery. 2012; 117(6):1141-9. [PubMed: 23039143]

76. Moro E, Hamani C, Poon YY, et al. Unilateral pedunculopontine stimulation improves falls in Parkinson's disease. Brain: a journal of neurology. 2010; 133(Pt 1):215-24. [PubMed: 19846583]

77. Weiss D, Walach M, Meisner C, et al. Nigral stimulation for resistant axial motor impairment in Parkinson's disease? A randomized controlled trial. Brain: a journal of neurology. 2013; 136(Pt 7): 2098-108. [PubMed: 23757762]

78. Ferraye MU, Debu B, Fraix V, et al. Effects of pedunculopontine nucleus area stimulation on gait disorders in Parkinson's disease. Brain: a journal of neurology. 2010; 133(Pt 1):205-14. [PubMed: 19773356]

79. Allen NE, Sherrington C, Paul SS, Canning CG. Balance and falls in Parkinson's disease: a metaanalysis of the effect of exercise and motor training. Movement disorders: official journal of the Movement Disorder Society. 2011; 26(9):1605-15. [PubMed: 21674624]

80. Li F, Harmer P, Fitzgerald K, et al. Tai chi and postural stability in patients with Parkinson's disease. The New England journal of medicine. 2012; 366(6):511-9. [PubMed: 22316445]

81. Seppi K, Weintraub D, Coelho M, et al. The Movement Disorder Society Evidence-Based Medicine Review Update: Treatments for the non-motor symptoms of Parkinson's disease. Movement disorders: official journal of the Movement Disorder Society. 2011; 26 (Suppl 3):S4280. [PubMed: 22021174]

82. Goldman JG, Holden S. Treatment of psychosis and dementia in Parkinson's disease. Current treatment options in neurology. 2014; 16(3):281. [PubMed: 24464490]

83. Emre M, Aarsland D, Albanese A, et al. Rivastigmine for dementia associated with Parkinson's disease. The New England journal of medicine. 2004; 351(24):2509-18. [PubMed: 15590953] 
84. Poewe W, Wolters E, Emre M, et al. Long-term benefits of rivastigmine in dementia associated with Parkinson's disease: an active treatment extension study. Movement disorders: official journal of the Movement Disorder Society. 2006; 21(4):456-61. [PubMed: 16229010]

85. Emre M, Poewe W, De Deyn PP, et al. Long-term Safety of Rivastigmine in Parkinson Disease Dementia: An Open-Label, Randomized Study. Clinical neuropharmacology. 2014; 37(1):9-16. [PubMed: 24434526]

86. Ravina B, Putt M, Siderowf A, et al. Donepezil for dementia in Parkinson's disease: a randomised, double blind, placebo controlled, crossover study. Journal of neurology, neurosurgery, and psychiatry. 2005; 76(7):934-9.

87. Litvinenko IV, Odinak MM, Mogil'naia VI, Emelin A. Efficacy and safety of galantamine (reminyl) in the treatment of dementia in patients with Parkinson's disease (open-label controlled trial). Zhurnal nevrologii i psikhiatrii imeni SS Korsakova/Ministerstvo zdravookhraneniia i meditsinskoi promyshlennosti Rossiiskoi Federatsii, Vserossiiskoe obshchestvo nevrologov [i] Vserossiiskoe obshchestvo psikhiat. 2007; 107(12):25-33.

88. Emre M, Tsolaki M, Bonuccelli U, et al. Memantine for patients with Parkinson's disease dementia or dementia with Lewy bodies: a randomised, double-blind, placebo-controlled trial. Lancet neurology. 2010; 9(10):969-77. [PubMed: 20729148]

89. Meltzer HY, Mills R, Revell S, et al. Pimavanserin, a serotonin(2A) receptor inverse agonist, for the treatment of parkinson's disease psychosis. Neuropsychopharmacology: official publication of the American College of Neuropsychopharmacology. 2010; 35(4):881-92. [PubMed: 19907417]

90**. Cummings J, Isaacson S, Mills R, et al. Pimavanserin for patients with Parkinson's disease psychosis: a randomised, placebo-controlled phase 3 trial. Lancet. 2014; 383(9916):533-40. In this trial a novel and unique drug pimvanserin, a selective serotonin 5-HT2A inverse agonist, showed to be benefit in the treatment of PDD without worsing motor symptoms. However randomized number was lower than expected. This is a promising drug mainly by the lack of treatments available for PDD. [PubMed: 24183563]

91. Liu J, Dong J, Wang L, et al. Comparative efficacy and acceptability of antidepressants in Parkinson's disease: a network meta-analysis. PloS one. 2013; 8(10):e76651. [PubMed: 24098546]

92. Troeung L, Egan SJ, Gasson N. A meta-analysis of randomised placebo-controlled treatment trials for depression and anxiety in Parkinson's disease. PloS one. 2013; 8(11):e79510. [PubMed: 24236141]

93. Chatterjee A, Fahn S. Methylphenidate treats apathy in Parkinson's disease. The Journal of neuropsychiatry and clinical neurosciences. 2002; 14(4):461-2. [PubMed: 12426416]

94. Czernecki V, Pillon B, Houeto JL, et al. Motivation, reward, and Parkinson's disease: influence of dopatherapy. Neuropsychologia. 2002; 40(13):2257-67. [PubMed: 12417456]

95. Devos D, Moreau C, Maltete D, et al. Rivastigmine in apathetic but dementia and depression-free patients with Parkinson's disease: a double-blind, placebo-controlled, randomised clinical trial. Journal of neurology, neurosurgery, and psychiatry. 2014; 85(6):668-74.

96. Sanchez-Ferro A, Benito-Leon J, Gomez-Esteban JC. The management of orthostatic hypotension in Parkinson's disease. Frontiers in neurology. 2013; 4:64. [PubMed: 23772219]

97. Mostile G, Jankovic J. Treatment of dysautonomia associated with Parkinson's disease. Parkinsonism \& related disorders. 2009; 15 (Suppl 3):S224-32. [PubMed: 20082997]

98. Hauser RA, Hewitt LA, Isaacson S. Droxidopa in patients with neurogenic orthostatic hypotension associated with Parkinson's disease (NOH306A). Journal of Parkinson's disease. 2014; 4(1):5765.

99. Ozekmekci S, Apaydin H, Kilic E. Clinical features of 35 patients with Parkinson's disease displaying REM behavior disorder. Clinical neurology and neurosurgery. 2005; 107(4):306-9. [PubMed: 15885389]

100. Boeve BF, Silber MH, Ferman TJ. Melatonin for treatment of REM sleep behavior disorder in neurologic disorders: results in 14 patients. Sleep medicine. 2003; 4(4):281-4. [PubMed: 14592300] 
101. Rios Romenets S, Creti L, Fichten C, et al. Doxepin and cognitive behavioural therapy for insomnia in patients with Parkinson's disease -- a randomized study. Parkinsonism \& related disorders. 2013; 19(7):670-5. [PubMed: 23561946]

102. Beiske AG, Loge JH, Ronningen A, Svensson E. Pain in Parkinson's disease: Prevalence and characteristics. Pain. 2009; 141(1-2):173-7. [PubMed: 19100686]

103. Sophie M, Ford B. Management of pain in Parkinson's disease. CNS drugs. 2012; 26(11):937-48. [PubMed: 23055368]

104. Rana AQ, Kabir A, Jesudasan M, et al. Pain in Parkinson's disease: analysis and literature review. Clinical neurology and neurosurgery. 2013; 115(11):2313-7. [PubMed: 24075714]

105. Troche MS, Okun MS, Rosenbek JC, et al. Aspiration and swallowing in Parkinson disease and rehabilitation with EMST: a randomized trial. Neurology. 2010; 75(21):1912-9. [PubMed: 21098406]

106. Ramig LO, Sapir S, Countryman S, et al. Intensive voice treatment (LSVT) for patients with Parkinson's disease: a 2 year follow up. Journal of neurology, neurosurgery, and psychiatry. 2001; 71(4):493-8.

107. Foster ER, Bedekar M, Tickle-Degnen L. Systematic review of the effectiveness of occupational therapy-related interventions for people with Parkinson's disease. The American journal of occupational therapy: official publication of the American Occupational Therapy Association. 2014; 68(1):39-49. [PubMed: 24367954]

108. van der Kolk NM, King LA. Effects of exercise on mobility in people with Parkinson's disease. Movement disorders: official journal of the Movement Disorder Society. 2013; 28(11):1587-96. [PubMed: 24132847] 


\section{KEY POINTS}

- Levodopa optimization is critical in the management of advanced PD and should include attention to absorption, timing, and dosages. Other pharmacological optimization strategies include the addition of a MAO-B inhibitor, a COMT inhibitor, a DA, and/or an extended-release levodopa formulation.

- Amantadine has been shown useful to suppress dyskinesia.

- DBS, LCIG and apomorphine continuous infusion treatment can be used in appropriately screened and selected PD patients. Currently DBS treatment has the highest level of evidence.

- Axial symptoms and NMS are considered hallmarks of advanced PD, and can be important predictors of an impaired quality of life. Treatment of depression should be aggressively pursued.

- Non-pharmacological treatments inclusive of physical therapy, occupational therapy, speech therapy, swallowing therapy and counseling psychology are all very helpful in the treatment of advanced PD. 
ADVANCED PD ALREADY ON LEVODOPA THERAPY

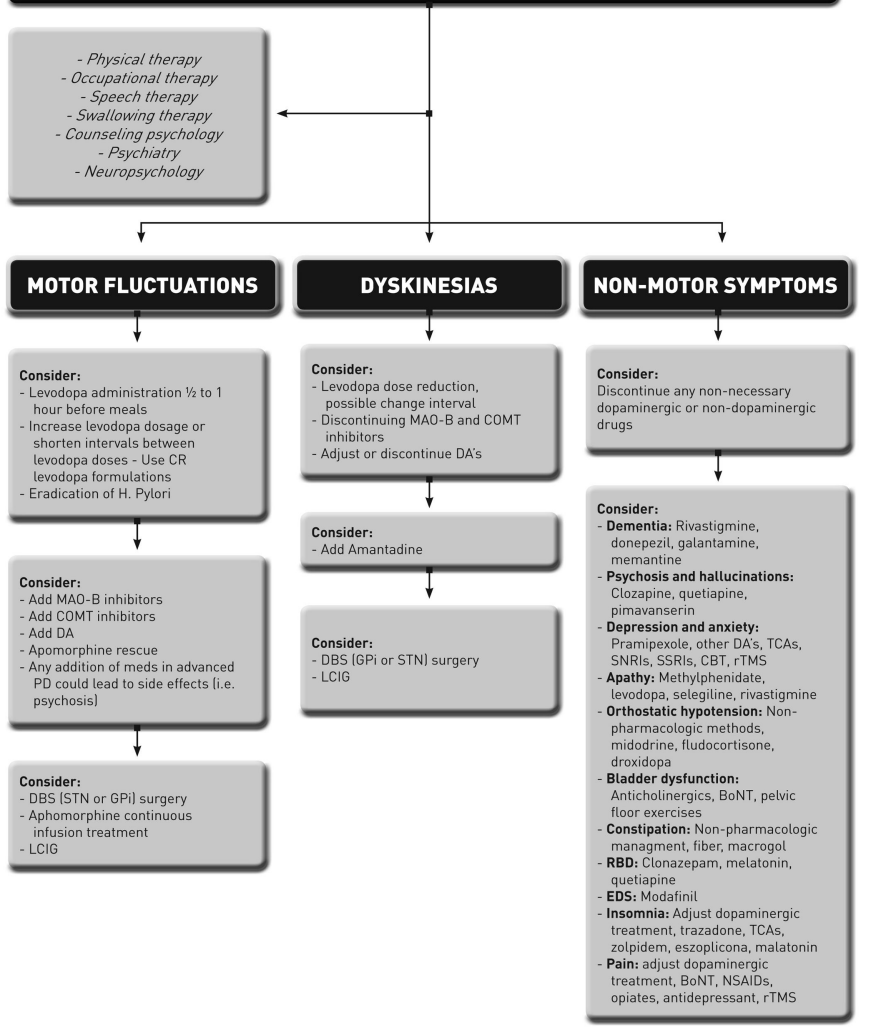

Figure 1. Suggested guideline for the management of advanced PD

H. Pylori, Helicobacter pylori; CR, controlled release; MAO-B, monoamine oxidase-B;

COMT, catechol-O-methyltransferase; DA, dopamine agonist; DBS, deep brain stimulation; STN, subthalamic nucleus; GPi globus pallidus interna; LCIG, levodopa carbidopa intestinal gel; TCAs, tricyclic antidepressant; SNRIs, serotonin and norepinephrine reuptake inhibitors; SSRIs, serotonin reuptake inhibitors; CBT, cognitive behavioral therapy; rTMS, repetitive transcranial magnetic stimulation; RBD, REM sleep behavior disorder; EDS, excessive daytime sleepiness; BoNT, botulinum toxin; NSAIDs, non-steroidal antiinflammatory drug. 


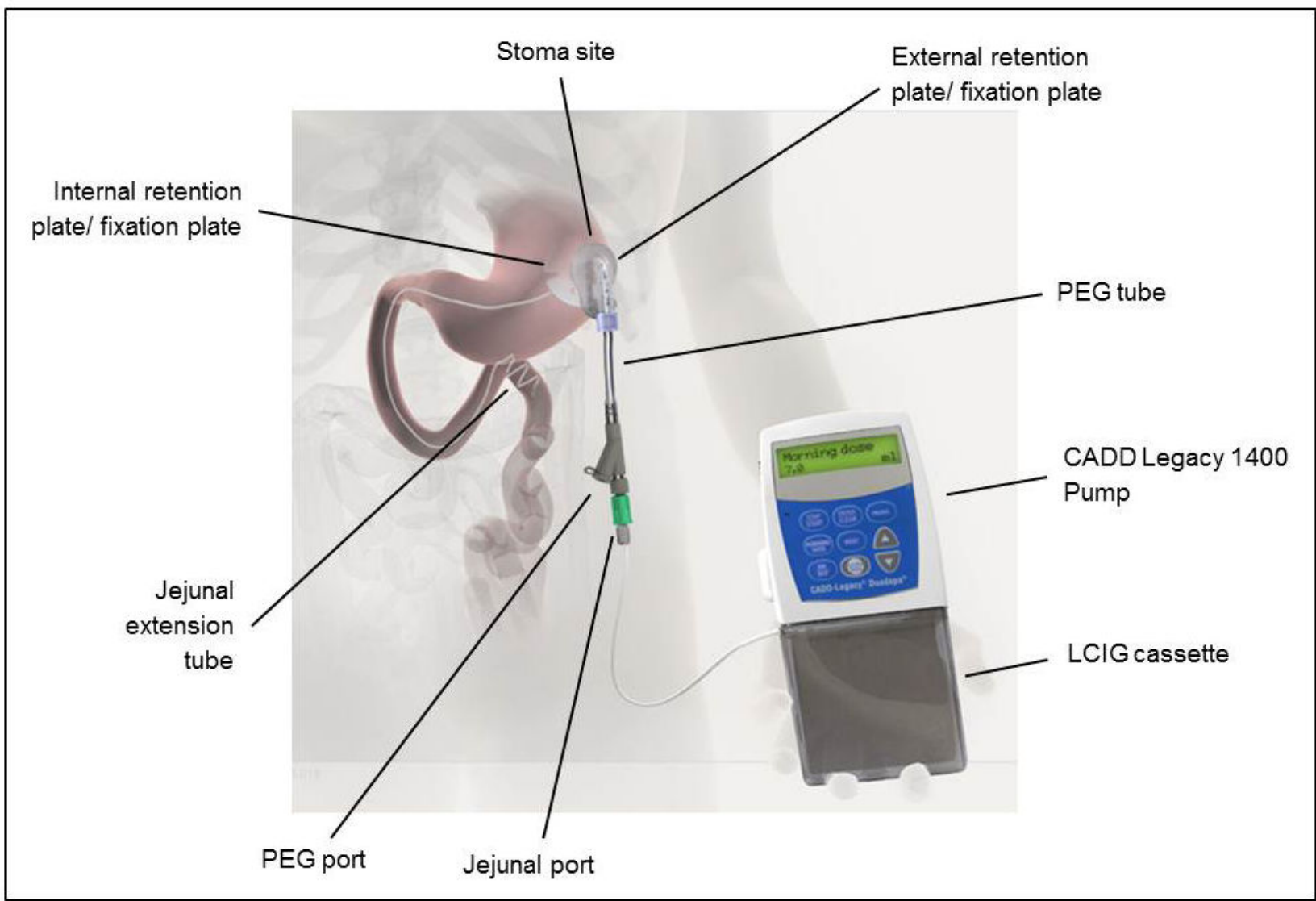

Figure 2. Levodopa carbidopa intestinal gel delivered system

Reproduced with permission from, Olanow CW, Kieburtz K, Odin P, et al. Continuous intrajejunal infusion of levodopa-carbidopa intestinal gel for patients with advanced Parkinson's disease: a randomised, controlled, double-blind, double-dummy study. Lancet neurology. 2014;13(2):141-9. (63) 

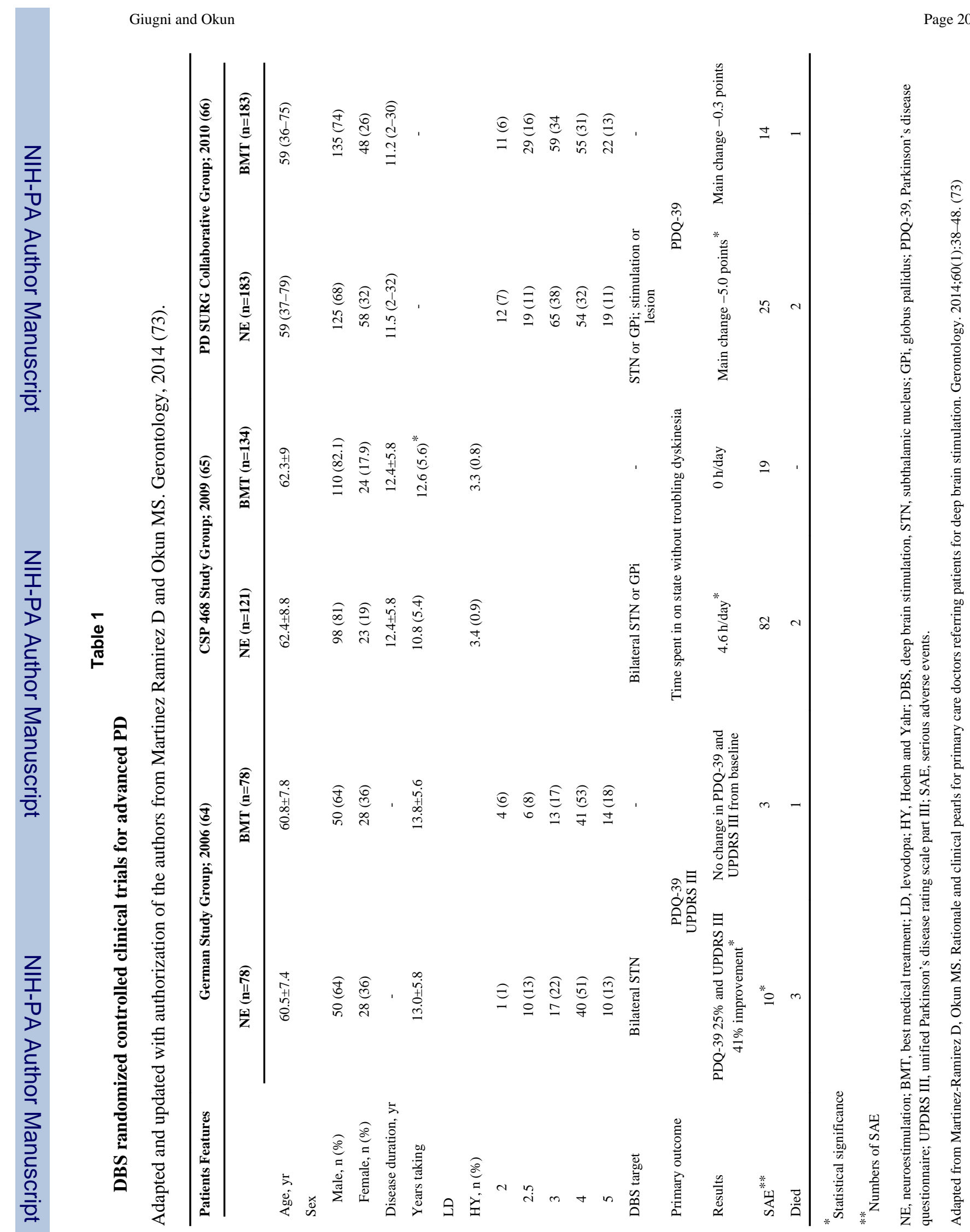

Curr Opin Neurol. Author manuscript; available in PMC 2015 August 01. 